\title{
The consumption of alcohol mixed with energy drinks: prevalence and key correlates among Canadian high school students
}

\author{
Sunday Azagba PhD, Don Langille MD MHSc, Mark Asbridge PhD
}

ABSTRACT

Background: An emerging body of research has reported high consumption of alcohol mixed with energy drinks among young adults, particularly college students. However, little is known about adolescents' consumption of these drinks. The purpose of this study was to determine the prevalence of consumption of alcohol mixed with energy drinks and to examine its correlates among Canadian high school students.

Methods: We used a nationally representative sample of 36155 Canadian students in grades 7 to 12 who participated in the 2010/2011 Youth Smoking Survey.

Results: About $20 \%$ of Canadian high school students reported consuming alcohol mixed with energy drinks in the last year, with considerable variation across provinces. Multivariate logistic regression analyses showed that the odds of consumption of these drinks were higher among students in lower grades (grades 7 and 8) and among students who identified their ethnicity as black or "other." Consumption of alcohol mixed with energy drinks was positively associated with substance use (current smoking [adjusted odds ratio (OR) 1.52, 95\% confidence interval (Cl) 1.19-1.95], past-year heavy drinking [adjusted OR 3.41, 95\% Cl 2.84-4.09] and marijuana use [adjusted OR 2.29, 95\% Cl 1.90-2.76]), absence from school, participation in school team sports and having more weekly spending money. Students who felt more connected to school and had an academic average of $70 \%$ or higher were less likely to consume alcohol mixed with energy drinks.

Interpretation: The consumption of alcohol mixed with energy drinks is an emerging public health concern. Consumption of these drinks is substantial among Canadian high school students and can lead to many potential harms, both acute (e.g., injury) and long term (e.g., increased alcohol dependence). Our findings highlight the need for further research into the long-term effects of consumption of alcohol mixed with energy drinks among young people, as well as the development of interventions aimed at reducing consumption of these drinks.

T he consumption of energy drinks, beverages that contain moderate to high concentrations of caffeine as well as taurine, herbal supplements, and sugar or sweeteners, has risen steadily in the last decade, ${ }^{1}$ with sales surpassing those of many other nonalcoholic beverages in North America., ${ }^{2,3}$ These beverages have become particularly popular among youth and young adults owing to their purported stimulant effects and ability to increase alertness and enhance mental and physical energy. ${ }^{1,47}$ Clinical studies have shown that the consumption of energy drinks increases stimulation, attention and memory; decreases reaction times and mental fatigue; and improves performance on some physical activities. ${ }^{8-10}$ At the same time, these beverages have been associated with negative health effects, including those typically associated with excess caffeine consumption, such as irritability, arrhythmia, nervousness, nausea and seizures. ${ }^{711-16}$

Despite warnings to the contrary, a popular practice among consumers of energy drinks is to mix them with alcohol..$^{1718}$
The combined effects of alcohol mixed with caffeine produce varied results on cognitive and motor performance. Because of increased feelings of alertness produced by caffeine, subjective estimates of alcohol impairment are typically underestimated, and the perceived rewarding aspects of drinking are enhanced. ${ }^{5,17,19-21}$ As such, consumption of alcohol mixed with energy drinks has been associated with greater risk-taking, impaired driving, higher volumes of alcohol consumption per sitting, increased injury susceptibility and higher rates of alcohol dependence. ${ }^{1,1,22-29}$ Other health consequences associated

Competing interests: None declared.

This article has been peer reviewed.

Correspondence to: Mark Asbridge, mark.asbridge@dal.ca

CMAJ Open 2013. DOI:10.9778/cmajo.20120017 
with consumption of these drinks include adverse physiologic stimulation and sexual assault. . $^{30,31}$

Largely absent from the literature are studies reporting on the prevalence of consumption of these drinks and important individual and social correlates. A handful of nonrepresentative, small-sample studies from Canada, the United States, Turkey and Italy have reported on consumption of these drinks among college students and noted that between 15\% and 85\% of energy drinks users mix them with alcohol..$^{28,29,32-35}$ Similarly, $\mathrm{O}^{\prime} B$ rien and colleagues ${ }^{25}$ found that nearly one-quarter of college students who had consumed alcohol in the previous 30 days had mixed it with an energy drink. The propensity to use alcohol mixed with energy drinks appears highest in youth and young adults, and in those who are white, unmarried, of higher income and involved in sport. ${ }^{29,36}$ To date, we lack understanding of the prevalence of consumption of these drinks, related individual and social correlates of use, and the associated health and social burden, particularly among those most vulnerable - youth and adolescents. We address these gaps by reporting on the prevalence and correlates of consumption of alcohol mixed with energy drinks in a nationally representative sample of Canadian high school students.

\section{Methods}

\section{Data}

We used nationally representative data from 36155 Canadian students in grades 7 to 12 from the 2010/2011 Youth Smoking Survey. A detailed description about the design and procedure of the survey has been documented elsewhere. ${ }^{37}$ Briefly, the Youth Smoking Survey is a cross-sectional, biennial classroombased survey that primarily contains information on tobaccorelated behaviours among students in the 10 Canadian provinces. The survey excludes students living in institutions, First Nations reserves, the Yukon Territory, Nunavut and the Northwest Territories, and those attending special schools (e.g., for students with visual or hearing impairment) or schools on military bases. The province of New Brunswick did not participate in the 2010/2011 Youth Smoking Survey. Although the Youth Smoking Survey included students in grades 6 to 12, in our study we used data for students in grades 7 to 12 because information on our outcome variable, use of alcohol mixed with energy drinks, was not collected for grade 6 students. The total response rate for the 2010/2011 Youth Smoking Survey at the school board level was $82 \%$; the response rate was $56 \%$ for schools and $73 \%$ for students. All protocol and materials of the Youth Smoking Survey received ethics approval from the University of Waterloo (the principal coordinator of the survey), Health Canada and institutions of consortium members where required. The Dalhousie University Research Ethics Board gave ethics approval for this research project.

\section{Measures}

\section{Dependent variable}

To determine use of alcohol mixed with energy drinks, respondents were asked whether they had consumed mixed or premixed (sold in a bottle or can) alcohol with an energy drink during the past 12 months. We created a dichotomous indicator for consumption of these drinks ( 1 if the response was "yes," 0 if "no").

\section{Independent variables}

Consistent with previous related studies ${ }^{29,36}$ a number of factors were included in the analysis. These covariates included the following: sex $(1=$ male); school grade level $(7,8,9,10,11$ and 12); risk-taking behaviours, including being a current smoker (yes v. no), past-year heavy drinking (drank $\geq 5$ on 1 occasion at least 12 times in the last year, compared with drank $\geq 5$ on 1 occasion fewer than 12 times in the last year and no drinking in the last year), past-year marijuana use (marijuana use in the last year v. no marijuana use in the last year); and academic average (grade average $\geq 70 \%$ v. $<70 \%$ ). School connectedness was measured according to how strongly students agreed or disagreed with 6 statements (score range 6-24, with higher score indicating greater school connectedness, Cronbach $\alpha=0.82$ ), such as "I feel close to people in my school" and "I feel I am part of my school"; absence from school in the past 4 weeks ( $\geq 3 \mathrm{~d}, 1-2 \mathrm{~d}$ or no absence); participation in 1 or more school team sports; weekly spending money $(\geq \$ 40$, unknown or $<\$ 40$ ); ethnic origin (Asian, Aboriginal, black, other [Hispanic or mixed-race] or white); and province of residence (Newfoundland and Labrador, Prince Edward Island, Quebec, Ontario, Manitoba, Saskatchewan, Alberta, British Columbia or Nova Scotia).

\section{Statistical analysis}

We used multivariate logistic regression analysis to examine the cross-sectional associations between the prevalence of consumption of alcohol mixed with energy drinks in the last year and risk-taking behaviours, individual school-related factors, weekly spending money, ethnic origin and province of residence. We examined 3 models: model 1 included all covariates with the exception of heavy drinking and province of residence, model 2 added heavy drinking to the analysis and model 3 added province of residence. Survey weights were used in all analyses to produce population estimates and adjust for the unequal probability of selection and student nonresponse.

\section{Results}

Table 1 presents weighted demographic characteristics of the 36155 students included in this study. About half of the students were female, and proportions of grade levels were approximately equal. About $10 \%$ of the male students and $7 \%$ of the female students identified themselves as smokers, whereas about $21 \%$ of the male students and $17 \%$ of the female students reported heavy drinking in the last year. Almost one-fifth of the students reported using marijuana in the last year (about $22 \%$ of the male students and $18 \%$ of the female students). More than two-thirds of the students reported they were white.

The prevalence of consumption of alcohol mixed with 


\begin{tabular}{|c|c|c|c|}
\hline \multirow[b]{2}{*}{ Characteristic } & \multicolumn{3}{|c|}{$\%$ of students* } \\
\hline & Total, $n=36155$ & Male, $n=17439$ & Female, $n=18716$ \\
\hline \multicolumn{4}{|l|}{ Grade level } \\
\hline 7 & 15.3 & 15.2 & 15.5 \\
\hline 8 & 16.0 & 16.0 & 16.0 \\
\hline 9 & 16.9 & 17.0 & 16.9 \\
\hline 10 & 17.5 & 17.8 & 17.2 \\
\hline 11 & 17.6 & 17.5 & 17.7 \\
\hline 12 & 16.6 & 16.5 & 16.7 \\
\hline \multicolumn{4}{|l|}{ Ethnic origin } \\
\hline White & 68.9 & 69.2 & 68.6 \\
\hline Asian & 12.3 & 11.9 & 12.6 \\
\hline Aboriginal & 3.3 & 3.5 & 3.2 \\
\hline Black & 3.1 & 3.3 & 2.9 \\
\hline Other & 12.4 & 12.1 & 12.7 \\
\hline \multicolumn{4}{|l|}{ Risk-taking behaviours } \\
\hline Smoker & 8.1 & 9.5 & 6.8 \\
\hline Nonsmoker & 91.9 & 90.5 & 93.2 \\
\hline Heavy drinking & 18.7 & 20.5 & 16.9 \\
\hline Less heavy drinking & 29.8 & 28.8 & 30.7 \\
\hline No drinking & 51.5 & 50.6 & 52.4 \\
\hline Marijuana use & 20.4 & 22.3 & 18.4 \\
\hline No marijuana use & 79.6 & 77.7 & 81.6 \\
\hline \multicolumn{4}{|l|}{ Individual school measures } \\
\hline Grade average $\geq 70 \%$ & 75.4 & 70.9 & 80.0 \\
\hline Grade average $<70 \%$ & 24.6 & 29.1 & 20.0 \\
\hline School connectedness, mean score out of 24 & 19.1 & 19.1 & 19.1 \\
\hline Absence from school $\geq 3$ days & 10.2 & 10.4 & 10.1 \\
\hline Absence from school 1-2 days & 14.9 & 14.2 & 15.6 \\
\hline No absence from school & 74.7 & 75.3 & 74.1 \\
\hline School team sports & 48.5 & 52.9 & 43.9 \\
\hline No school team sports & 51.5 & 47.1 & 56.1 \\
\hline \multicolumn{4}{|l|}{ Weekly spending money } \\
\hline$\geq \$ 40$ & 19.6 & 19.9 & 19.3 \\
\hline$<\$ 40$ & 68.0 & 69.2 & 66.7 \\
\hline Unknown & 12.4 & 10.9 & 13.9 \\
\hline \multicolumn{4}{|l|}{ Province of residence } \\
\hline Newfoundland and Labrador & 1.5 & 1.3 & 1.6 \\
\hline Prince Edward Island & 0.5 & 0.5 & 0.5 \\
\hline Nova Scotia & 2.7 & 2.7 & 2.8 \\
\hline Quebec & 19.9 & 20.1 & 19.7 \\
\hline Ontario & 43.2 & 43.4 & 43.0 \\
\hline Manitoba & 3.9 & 3.9 & 4.0 \\
\hline Saskatchewan & 3.2 & 3.1 & 3.2 \\
\hline Alberta & 12.1 & 11.9 & 12.4 \\
\hline British Columbia & 13.0 & 13.1 & 12.8 \\
\hline
\end{tabular}


energy drinks in the last year by selected characteristics (sex, grade level, ethnic origin and province of residence) is shown in Figures 1 and 2. About 20\% of participants reported using alcohol mixed with energy drinks in the last year. The prevalence of use was highest among Aboriginal (33.8\%) and black (25\%) students, and among those residing in British Colum- bia $(25.8 \%)$ and Nova Scotia (25.6\%). Use of alcohol mixed with energy drinks was higher among those in higher grades and among those who were older.

Multivariate logistic regression results are presented in Table 2. Model 1 included all covariates with the exception of heavy drinking and province of residence; model 2 included

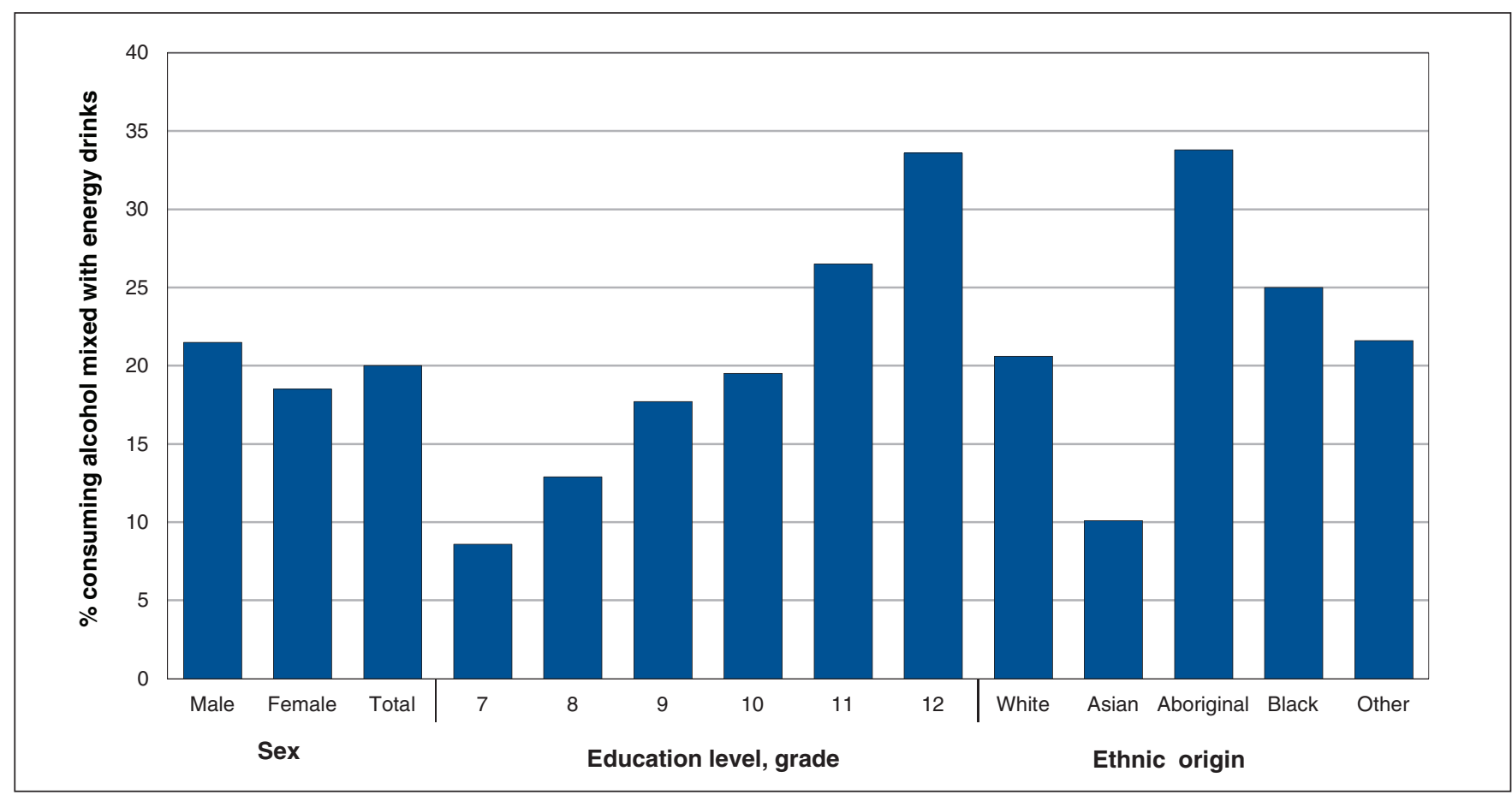

Figure 1: Prevalence of consumption of alcohol mixed with energy drinks by sex, grade level and ethnic origin.

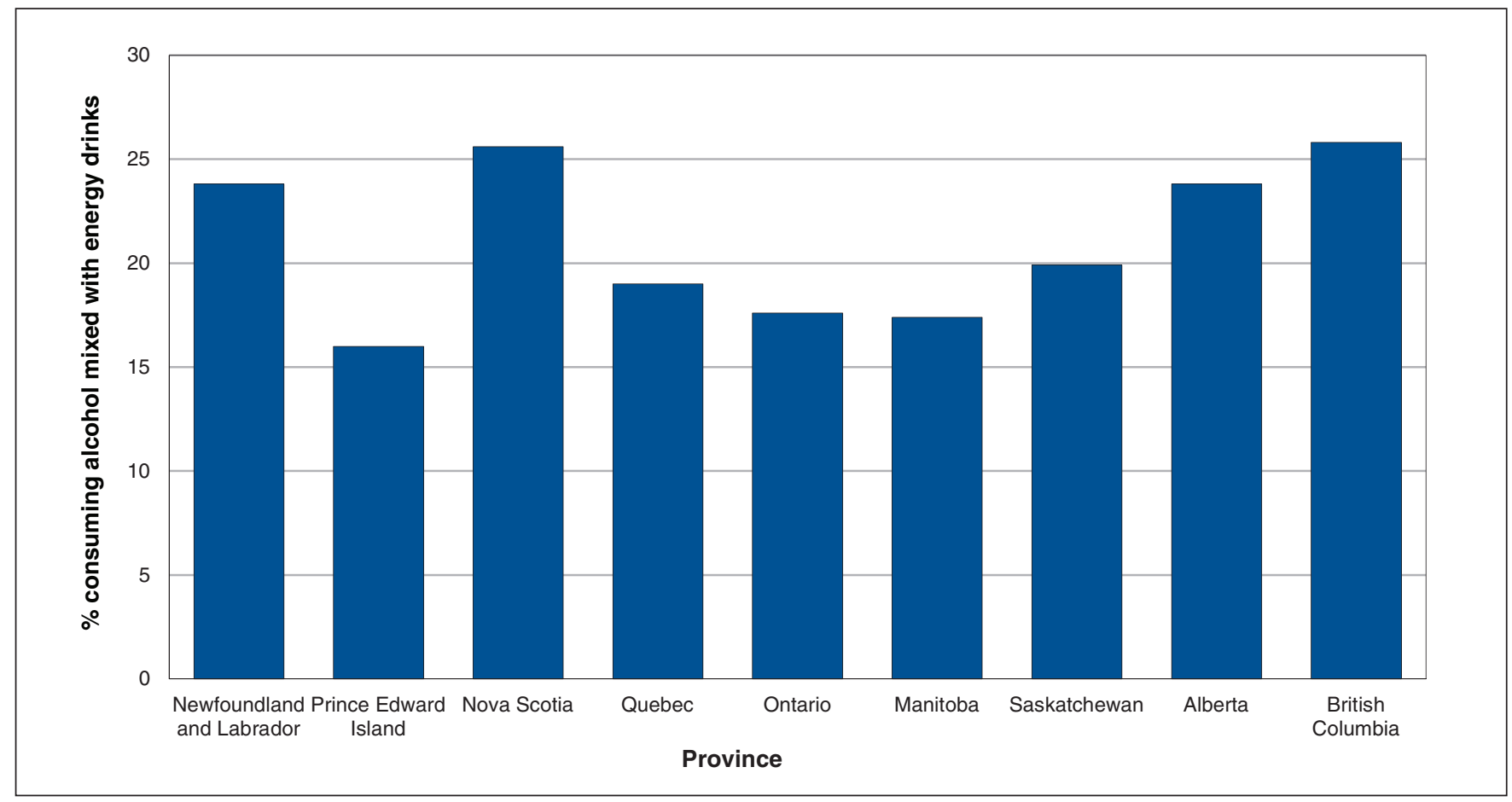

Figure 2: Prevalence of consumption of alcohol mixed with energy drinks by province of residence. 
heavy drinking in the analysis and model 3 included province of residence. Findings were generally consistent across models. Results of model 3 showed that students who were in grade 7 (odds ratio [OR] 1.63, 95\% confidence interval [CI] 1.22-2.20) and grade 8 (OR 1.52, 95\% CI 1.15-2.01), currently smoked (OR 1.52, 95\% CI 1.19-1.95), were involved in heavy drinking in the past year (OR 3.41, 95\% CI 2.84-4.09), used marijuana in the past year (OR 2.29, 95\% CI 1.90-2.76), were absent from school ( $\geq 3$ d: OR 2.06, 95\% CI 1.60-2.65; 1-2 d: OR 1.26, 95\% CI 1.04-1.52), participated in school team sports (OR 1.16, 95\% CI 1.01-1.34) and had $\$ 40$ or more weekly spending money (OR 1.51, 95\% CI 1.27-1.80) were more likely to consume alcohol mixed with energy drinks in the previous year. Similarly, students who felt more connected to school (OR 0.96, 95\% CI 0.93-0.98) and who had an academic average of $70 \%$ or higher (OR $0.80,95 \%$ CI 0.68-0.94) were less likely to consume these drinks. The results confirmed provincial differences in the prevalence of consumption. Students residing in Newfoundland and Labrador (OR 0.82, 95\% CI 0.71-0.95), Prince Edward Island (OR 0.66, 95\% CI 0.56-0.78), Quebec (OR 0.70, 95\%
CI 0.57-0.86), Manitoba (OR 0.65, 95\% CI 0.56-0.76) and Saskatchewan (OR 0.64, 95\% CI 0.52-0.78) were less likely to consume these drinks than those residing in Nova Scotia.

Sex was not associated with use of alcohol mixed with energy drinks, and a sex-stratified analysis (not presented) revealed similar associations between risk-taking behaviours and consumption of these drinks among male and female students across all 3 models.

One observed difference in models is related to use of alcohol mixed with energy drinks among students in grades 7 and 8 . In model 1 , students in these grades had lower odds of consuming these drinks; however, the association reversed with adjustment for heavy drinking, such that students in grades 7 and 8 had higher odds of consumption.

\section{Interpretation}

We carried out an analysis of a nationally representative sample of Canadian high school students to determine the prevalence and social determinants of use of alcohol mixed with energy drinks. Among 36155 youth in grades 7 to 12 in

\begin{tabular}{|c|c|c|c|}
\hline \multirow[b]{2}{*}{ Variable } & \multicolumn{3}{|c|}{ Adjusted OR (95\% Cl) } \\
\hline & Model 1 & Model 2 & Model 3 \\
\hline \multicolumn{4}{|l|}{ Sex } \\
\hline Male & $1.07(0.93-1.23)$ & $1.08(0.94-1.24)$ & $1.09(0.94-1.25)$ \\
\hline Female & 1 & 1 & 1 \\
\hline \multicolumn{4}{|l|}{ Grade level } \\
\hline 7 & $0.65(0.50-0.86)$ & $1.49(1.10-2.01)$ & $1.63(1.22-2.20)$ \\
\hline 8 & $0.79(0.62-1.02)$ & $1.40(1.06-1.84)$ & $1.52(1.15-2.01)$ \\
\hline 9 & $0.85(0.67-1.08)$ & $1.14(0.89-1.47)$ & $1.24(0.96-1.60)$ \\
\hline 10 & $0.73(0.58-0.92)$ & $0.84(0.66-1.07)$ & $0.89(0.70-1.14)$ \\
\hline 11 & $0.87(0.69-1.09)$ & $0.86(0.68-1.08)$ & $0.90(0.72-1.14)$ \\
\hline 12 & 1 & 1 & 1 \\
\hline \multicolumn{4}{|l|}{ Ethnic origin } \\
\hline Asian & $0.60(0.42-0.86)$ & $0.89(0.62-1.27)$ & $0.88(0.62-1.26)$ \\
\hline Aboriginal & $1.25(1.00-1.66)$ & $1.25(0.98-1.61)$ & $1.23(0.95-1.57)$ \\
\hline Black & $1.05(0.68-1.65)$ & $1.48(0.93-2.37)$ & $1.48(0.93-2.35)$ \\
\hline Other & $1.01(0.82-1.25)$ & $1.32(1.05-1.66)$ & $1.30(1.03-1.64)$ \\
\hline White & 1 & 1 & 1 \\
\hline \multicolumn{4}{|c|}{ Risk-taking behaviours } \\
\hline Current smoker & $2.01(1.54-2.64)$ & $1.51(1.18-1.94)$ & $1.52(1.19-1.95)$ \\
\hline Nonsmoker & 1 & 1 & 1 \\
\hline Heavy drinking & & $3.40(2.83-4.08)$ & $3.41(2.84-4.09)$ \\
\hline No drinking & & $0.26(0.21-0.32)$ & $0.25(0.21-0.30)$ \\
\hline Light drinking & 1 & 1 & 1 \\
\hline Marijuana use & $4.49(3.80-5.31)$ & $2.30(1.91-2.77)$ & $2.29(1.90-2.76)$ \\
\hline No marijuana use & 1 & 1 & 1 \\
\hline
\end{tabular}




\begin{tabular}{|c|c|c|c|}
\hline \multirow[b]{2}{*}{ Variable } & \multicolumn{3}{|c|}{ Adjusted OR (95\% Cl) } \\
\hline & Model 1 & Model 2 & Model 3 \\
\hline \multicolumn{4}{|l|}{ Individual school measures } \\
\hline Grade average $\geq 70 \%$ & $0.76(0.65-0.89)$ & $0.79(0.67-0.93)$ & $0.80(0.68-0.94)$ \\
\hline Grade average $<70 \%$ & 1 & 1 & 1 \\
\hline School connectedness & $0.94(0.92-0.96)$ & $0.95(0.93-0.97)$ & $0.96(0.93-0.98)$ \\
\hline Absence from school $\geq 3$ days & $2.70(2.16-3.37)$ & $2.00(1.56-2.57)$ & $2.06(1.60-2.65)$ \\
\hline Absence from school 1-2 days & $1.66(1.36-2.02)$ & $1.24(1.03-1.50)$ & $1.26(1.04-1.52)$ \\
\hline No absence from school & 1 & 1 & 1 \\
\hline School team sports & $1.29(1.12-1.48)$ & $1.17(1.01-1.35)$ & $1.16(1.01-1.34)$ \\
\hline No school team sports & 1 & 1 & 1 \\
\hline \multicolumn{4}{|l|}{ Weekly spending money } \\
\hline$\geq \$ 40$ & $1.51(1.26-1.79)$ & $1.51(1.26-1.79)$ & $1.51(1.27-1.80)$ \\
\hline Unknown & $1.14(0.88-1.47)$ & $1.07(0.85-1.35)$ & $1.06(0.84-1.34)$ \\
\hline$<40$ & 1 & 1 & 1 \\
\hline \multicolumn{4}{|l|}{ Province of residence } \\
\hline Newfoundland and Labrador & & & $0.82(0.71-0.95)$ \\
\hline Prince Edward Island & & & $0.66(0.56-0.78)$ \\
\hline Quebec & & & $0.70(0.57-0.86)$ \\
\hline Ontario & & & $0.87(0.75-1.00)$ \\
\hline Manitoba & & & $0.65(0.57-0.76)$ \\
\hline Saskatchewan & & & $0.64(0.52-0.78)$ \\
\hline Alberta & & & $0.98(0.78-1.22)$ \\
\hline British Columbia & & & $0.96(0.80-1.15)$ \\
\hline Nova Scotia & & & 1 \\
\hline Observations & 36709 & 36155 & 36155 \\
\hline
\end{tabular}

Canada, about 1 in 5 had consumed these drinks in the previous year $(21.5 \%$ of male students and $18.5 \%$ of female students). These findings are in keeping with previous evidence drawn from studies of college students in Canada, the US and other jurisdictions, which reported that mixing alcohol with energy drinks was common. ${ }^{25,34} \mathrm{We}$ found considerable provincial variation in the prevalence of consumption. Respondents in Nova Scotia and British Columbia reported the highest rates of consumption, with lower rates observed in Prince Edward Island, Manitoba and Ontario. It is not apparent, however, whether these provincial differences reflect variations in availability of energy drinks, product price or provincial taxes.

With adjustment for other risk factors, the consumption of these drinks also varied considerably among certain subgroups of students. The use of alcohol mixed with energy drinks was increased among students who were younger, had used psychoactive substances, were frequently absent from school, were involved in sports and had more spending money. Pro- tective factors included performing well in school and reporting stronger feelings of school connectedness. It is not surprising that other risk-taking behaviours, including smoking, drinking (including heavy drinking) and marijuana use, were strongly associated with use of alcohol mixed with energy drinks. Risk-taking behaviours are known to cluster in Canadian youth, ${ }^{38}$ and policies and programs that address only one concern (such as alcohol mixed with energy drinks) may not be successful if underlying issues are not addressed.

As seen here, school-related issues, including school connectedness, academic performance and school absences, were strongly related to use of alcohol mixed with energy drinks. Among these, school connectedness, which is also related to smoking, marijuana use and heavy drinking, ${ }^{39,40}$ is perhaps most amenable to change. A study of elementary schools in Seattle, Washington, showed that teacher training in classroom management to enhance school bonding, parent training to promote family and school bonding, and student train- 
ing in social competency positively affected students' attitudes toward school, increased levels of school attachment, and reduced substance use and related risk-taking behaviours. ${ }^{41}$ Such an approach can be implemented by schools, which can develop and tailor the conditions that would most enhance the school environment.

Participation in sports is often believed, perhaps incorrectly, to be preventive of risk-taking among young people; ${ }^{42,43}$ however, we found that participation in school sports increased the risk of the consumption of alcohol mixed with energy drinks. This association has also been observed in a study of students from 10 universities in North Carolina. Of note, this study found an association between use of alcohol mixed with energy drinks and participation in intramural sports, but not participation in varsity sports. ${ }^{25}$ It has been suggested that there may be 2 kinds of athletes, the "jock" who participates in a limited number of sports that emphasize contact, high performance and traditional notions of masculinity, and the more prosocial student athlete with serious academic intentions. ${ }^{15}$ We were not able to make such a distinction; however, school athletic directors and coaches should be aware of the potential for use of alcohol mixed with energy drinks among students who participate in school sports.

Finally, the prevalence of consumption of alcohol mixed with energy drinks increased with increasing age; yet, with adjustment for other risk factors, consumption was highest among students in younger grades. This finding reflects differences in observed rates of drinking among students of different ages. A lower percentage of younger students (grade 7) drink alcohol $(10 \%)$ compared with students in grades $11(65 \%)$ and 12 (69\%), yet a higher proportion of these young drinkers mix alcohol with energy drinks. More concerning, however, is that although there exists no minimum age for the purchase and consumption of energy drinks in Canada, for most students participating in the survey, the use of alcohol is illegal (legal drinking age is 18 years in Alberta, Manitoba and Quebec, and 19 years in all other provinces). Although we may set our sights on addressing the practice of mixing alcohol with energy drinks, the fundamental concern remains underage drinking. Trend data from Ontario ${ }^{44}$ indicate that the prevalence of past-year alcohol consumption among students decreased from $70 \%$ in the late 1970 s to $50 \%$ in the early 1990 s, where it has remained for the last 20 years. This stability exists despite the presence of considerable programs, interventions and other resources in the school and the community directed at reducing underage drinking.

\section{Limitations}

Our study is limited in several ways. First, it is cross-sectional, so that only claims of association, but not causation, can be made about the observed relations between use of alcohol mixed with energy drinks and other risk-taking behaviour. Second, the data are self-reported and thus subject to response bias, particularly when dealing with questions of a sensitive nature such as those on substance use. Third, the survey does not include key social determinants, including appropriate measures of socioeconomic status (i.e., family income or relative wealth) and family structure, as well as key confounders, such as depression, impulsivity and poor mental health. ${ }^{45,46}$ The survey also did not include measures of use of energy drinks alone and frequency of consumption of alcohol mixed with energy drinks. Therefore, we were unable to provide a rate of overall consumption of energy drinks or examine the intensity at which alcohol mixed with energy drinks was consumed. Finally, the province of New Brunswick was not involved in the current survey, which has a marginal impact on the overall generalizability of results. Of note, previous cycles of the Youth Smoking Survey with complete data did not have information on alcohol mixed with energy drinks.

\section{Policy implications and future research}

This study reports on the prevalence of consumption of alcohol mixed with energy drinks in a large, nationally representative sample of school-aged youth. Our finding that $20 \%$ of Canadian high school students had consumed these drinks in the previous year raises a number of important questions about how best to move forward. Given that individuals who use alcohol mixed with energy drinks, relative to alcohol alone, are less able to recognize the symptoms of intoxication, and report greater risk-taking, higher susceptibility to injury and increased alcohol consumption in the short term, along with neurologic complications and higher alcohol dependence, ${ }^{1,16,22-31}$ opportunities to intervene by health policy-makers, clinicians and programmers responsible for youth are necessary. Health Canada, along with the US Food and Drug Administration (FDA), warn against the mixing of energy drinks with alcohol, and the FDA has moved to eliminate such "premixed" beverages from the market. However, self-mixing remains widespread. ${ }^{17,47,48}$ Given that youth continue to drink alcohol illegally, alternative strategies may be more effective than top-down, abstinence-based programs. At the policy level, this may take the form of a flat tax on energy drinks, or a variable tax reflective of caffeine content, similar to what is done with alcohol in certain jurisdictions (e.g., Saskatchewan). ${ }^{49}$ Conversely, schools and community services may adopt innovative harm-reduction approaches, assisted by social media, which encourage youth not to mix alcohol with energy drinks, without directly focusing on the use of either substance, per se. Schools and clinicians need to be aware of the extent of consumption of alcohol mixed with energy drinks among Canadian youth, and play a major role in educating and directing young people away from this potentially dangerous practice. Further research is needed on the consumption pattern of alcohol mixed with energy drinks among adolescents and its long-term impact on health, and to explore the provincial variation of consumption in Canada.

\section{References}

1. Reissig CJ, Strain EC, Griffiths RR. Caffeinated energy drinks: a growing problem. Drug Alcobol Depend 2009;99:1-10.

2. New report predicts energy drink sales in the U.S. to exceed $\$ 9$ billion by 2011 [press release]. England: Report Buyer; 2007. Available: www.reportbuyer.com /press/new-report-predicts-energy-drink-sales-in-the-us-to-exceed-9-billion-by -2011/ (accessed 2012 Nov. 3).

3. 2012 State of the industry report. Troy (MI): Beverage Industry; 2012. Available: www.bevindustry.com/articles/85663-2012-state-of-the-industry-report (accessed 2012 Oct. 30). 
4. Oddy WH, O'Sullivan TA. Energy drinks for children and adolescents, erring on the side of caution may reduce long term health risks. BM7 2009;339:b5268.

5. Arria AM, O'Brien MC. The "high" risk of energy drinks. FAMA 2011;305: 600-1.

6. Babu KM, Church RJ, Lewander W. Energy drinks: the new eye-opener for adolescents. Clin Pediatr Emerg Med 2008;9:35-42.

7. Seifert SM, Schaechter JL, Hershorin ER, et al. Health effects of energy drinks on children, adolescents, and young adults. Pediatrics 2011;127:511-28.

8. Howard MA, Marczinski CA. Acute effects of a glucose energy drink on behavioral control. Exp Clin Psychopharmacol 2010;18:553-61.

9. Alford C, Cox H, Wescott R. The effects of Red Bull energy drink on human performance and mood. Amino Acids 2001;21:139-50.

10. Scholey AB, Kennedy DO. Cognitive and physiological effects of an "energy drink": an evaluation of the whole drink and of glucose, caffeine and herbal flavouring fractions. Psychopharmacology (Berl) 2004;176:320-30.

11. Iyadurai SJ, Chung SS. New-onset seizures in adults: possible association with consumption of popular energy drinks. Epilepsy Behav 2007;10:504-8.

12. Taste for quick boost tied to taste for risk. The New York Times 2008 May 27. Available: www.nytimes.com/2008/05/27/health/27well.html?n=Top/Reference /Times\%20Topics/People/P/Parker-Pope,\%20Tara (accessed 2011 Jan. 17).

13. Savoca MR, MacKey L, Evans CD, et al. Association of ambulatory blood pressure and dietary caffeine in adolescents. Am 7 Hypertens 2005;18:116-20.

14. Orbeta RL, Overpeck MD, Ramcharran D, et al. High caffeine intake in adolescents: associations with difficulty sleeping and feeling tired in the morning. 7 Adolesc Health 2006;38:451-3.

15. Miller KE. Wired: energy drinks, jock identity, masculine norms, and risk taking. 7 Am Coll Health 2008;56:481-9.

16. Miller KE. Energy drinks, race, and problem behaviors among college students. 7 Adolesc Health 2008;43:490-7.

17. Caffeinated alcohol beverages. Silver Spring (MD): US Food and Drug Administration; 2010. Available: www.fda.gov/food/foodingredientspackaging/ucm 190366.htm (accessed 2012 Nov. 6).

18. Safe use of energy drinks. Ottawa (ON): Health Canada. Available: www.hc-sc .gc.ca/hl-vs/iyh-vsv/food-aliment/boissons-energ-drinks-eng.php (accessed 2012 Dec. 14).

19. Weldy DL. Risks of alcoholic energy drinks for youth. 7 Am Board Fam Med 2010;23:555-8

20. Marczinski CA, Fillmore MT, Bardgett ME, et al. Effects of energy drinks mixed with alcohol on behavioral control: risks for college students consuming trendy cocktails. Alcobol Clin Exp Res 2011;35:1282-92.

21. Kunin D, Gaskin S, Rogan F, et al. Caffeine promotes ethanol drinking in rates. Examination using a limited-access free choice paradigm. Alcohol 2000;21:271-7.

22. Ferreira SE, de Mello MT, Pompeia S, et al. Effects of energy drink ingestion on alcohol intoxication. Alcohol Clin Exp Res 2006;30:598-605.

23. Arria AM, Caldeira KM, Kasperski SJ, et al. Energy drink consumption and increased risk for alcohol dependence. Alcohol Clin Exp Res 2011;35:365-75.

24. Arria AM, Caldeira KM, Kasperski SJ, et al. Increased alcohol consumption, nonmedical prescription drug use, and illicit drug use are associated with energy drink consumption among college students. F Addict Med 2010;4:74-80.

25. O'Brien MC, McCoy TP, Rhodes SD, et al. Caffeinated cocktails: energy drink consumption, high-risk drinking, and alcohol-related consequences among college students. Acad Emerg Med 2008;15:453-60.

26. Thombs DL, O'Mara RJ, Tsukamoto $M$, et al. Event-level analyses of energy drink consumption and alcohol intoxication in bar patrons. Addict Behav 2010; 35:325-30.

27. Price SR, Hilchey CA, Darredeau C, et al. Energy drink co-administration is associated with increased reported alcohol ingestion. Drug Alcobol Rev 2010;29: 331-3.

28. Brache K, Stockwell T. Drinking patterns and risk behaviors associated with combined alcohol and energy drink consumption in college drinkers. Addict Behav 2011;36:1133-40

29. Woolsey C, Waigandt A, Beck NC. Athletes and energy drinks: reported risktaking and consequences from the combined use of alcohol and energy drinks. 7 Appl Sport Psychol 2010;22:65-71.

30. Miller KE. Alcohol mixed with energy drink use and sexual risk-taking: casual, intoxicated, and unprotected sex. 7 Caffeine Res 2012; DOI 10.1089/caf.2012.0015.

31. Peacock A, Bruno R, Martin FH. The subjective physiological, psychological, and behavioral risk-taking consequences of alcohol and energy drink co-ingestion. Alcobol Clin Exp Res 2012;36:2008-15.

32. Attila S, Cakir B. Energy-drink consumption in college students and associated factors. Nutrition 2011;27:316-22.
33. Oteri A, Salvo F, Caputi AP, et al. Intake of energy drinks in association with alcoholic beverages in a cohort of students of the school of Medicine of the University of Messina. Alcohol Clin Exp Res 2007;31:1677-80.

34. Malinauskas BM, Aeby VG, Overton RF, et al. A survey of energy drink consumption patterns among college students. Nutr 7 2007;6:35.

35. Velazquez CE, Poulos NS, Latimer LA, et al. Associations between energy drink consumption and alcohol use behaviors among college students. Drug Alcohol Depend 2012;123:167-72.

36. Berger LK, Fendrich M, Chen H-Y, et al. Sociodemographic correlates of energy drink consumption with and without alcohol: results of a community survey. Addict Behav 2011;36:516-9.

37. Elton-Marshall T, Leatherdale ST, Manske SR, et al. Research methods of the Youth Smoking Survey (YSS). Chronic Dis Inj Can 2011;32:47-54.

38. Poulin C, Elliott D. Alcohol, tobacco and cannabis use among Nova Scotia adolescents: implications for prevention and harm reduction. CMA7 1997;156: 1387-93.

39. Prado G, Huang S, Schwartz SJ, et al. What accounts for differences in substance use among U.S.-born and immigrant Hispanic adolescents?: results from a longitudinal prospective cohort study. 7 Adolesc Health 2009;45:118-25.

40. Bond L, Butler H, Thomas L, et al. Social and school connectedness in early secondary school as predictors of late teenage substance use, mental health, and academic outcomes. 7 Adolesc Health 2007;40:357e9-357e18.

41. Hawkins JD, Catalano RF, Kosterman R, et al. Preventing adolescent health-risk behaviors by strengthening protection during childhood. Arch Pediatr Adolesc Med 1999;153:226-34.

42. Eitle D, Turner RJ, Eitle TM. Deterrence hypothesis reexamined: sports participation and substance use among young adults. 7 Drug Issues 2003;33:193-222.

43. Peck SC, Vida M, Eccles JS. Adolescent pathways to adulthood drinking: Sport activity involvement is not necessarily risky or protective. Addiction 2008; 103(Suppl 1):69-83.

44. Paglia-Boak A, Adlaf EM, Mann RE. Drug use among Ontario students, 1977 2011: Detailed OSDUHS findings. (CAMH research document series no. 32). Toronto (ON): Centre for Addiction and Mental Health; 2011.

45. Fergusson DM, Boden JM, Horwood LJ. Tests of causal links between alcohol abuse or dependence and major depression. Arch Gen Psychiatry 2009;66:260-6.

46. Gullo MJ, Dawe S. Impulsivity and adolescent substance use: Rashly dismissed as "all-bad"? Neurosci Biobehav Rev 2008;32:1507-18.

47. Safe use of energy drinks. Ottawa (ON): Health Canada; 2010. Available: www.refreshments.ca/8-what-we-produce/11-energy-drinks/133-health-canada -safe-use-of-energy-drinks (accessed 2012 Dec. 14).

48. Health Canada's proposed approach to managing caffeinated energy drinks. Ottawa (ON): Health Canada; 2011. Available: www.hc-sc.gc.ca/fn-an/legislation /pol/energy-drinks-boissons-energisantes-eng.php (accessed 2012 Aug. 22).

49. Stockwell T, Zhao J, Giesbrecht N, et al. The raising of minimum alcohol prices in Saskatchewan, Canada: impacts on consumption and implications for public health. Am F Public Health 2012;102:e103-10.

Affiliations: From the Department of Community Health and Epidemiology, Dalhousie University, Halifax, NS

Contributors: Sunday Azagba, Mark Asbridge and Don Langille conceived and designed the study. Sunday Azagba analyzed the data. All authors contributed to the writing of the manuscript and all authors approved the final version submitted for publication.

Funding: Mark Asbridge was supported by a Canadian Institutes for Health Research New Investigator Award. Sunday Azagba is funded, in part, from a Scotia Support Grant from the Nova Scotia Health Research Foundation. This research was supported by a grant from AUTO21, a member of the Networks of Centres of Excellence program, which is administered and funded by the Natural Sciences and Engineering Research Council, the Canadian Institutes of Health Research, and the Social Sciences and Humanities Research Council, in partnership with Industry Canada.

Supplemental information: For reviewer comments and the original submission of this manuscript, please see www.cmajopen.ca/content/1/1 /E19/suppl/DC1 